\title{
Rechtsgeschichte
}

http://www.rg-rechtsgeschichte.de/rg1

Zitiervorschlag: Rechtsgeschichte Rg 1 (2002)

$\operatorname{Rg} 2002$

$284-285$

http://dx.doi.org/10.12946/rg01/284-285

\section{Marie Theres Fögen}

Gesteht! 
wurden Bestandteil der Akten. Eine gerichtsfixierte Prozessaktenforschung konnte mit diesen Fremdkörpern nichts anfangen, sonderte sie aus und legte sie in Extra-Kästen für »Unwichtiges «. Erst heute, mit dem für kulturelle Techniken aufmerksamen Blick, rücken diese Karten als eine bestimmte Form visualisierter Wirklichkeit ins Zentrum historischen Interesses. - An den Gerichtsakten des Alten Reichs gäbe es also tatsächlich noch Neues zu entdecken.

\section{Cornelia Vismann}

\section{Gesteht!*}

Als r968 »Die unbegrenzte Auslegung « erschien, ${ }^{\text {I }}$ da war's wie Donnerhall. Hatten doch die damals Studierenden gerade begonnen, die alten Biedermänner, die man ihnen als Rechtslehrer vorgesetzt hatte, als ehemalige Brandstifter zu entlarven. Bernd Rüthers goss Öl in den schwelenden Zorn, indem er die Legenden vom unpolitischen Zivilrecht zerstörte und die personellen und weltanschaulichen Kontinuitäten zwischen NS-Zeit und Bundesrepublik aufdeckte. "Die unbegrenzte Auslegung « gehörte zu den Aha-Erlebnissen einer gerade erst unruhig gewordenen Generation von jungen Juristinnen und Juristen, sogar derjenigen, die politisch immun und unverdrossen durchs Studium trotteten. Stand der Jungakademiker Rüthers doch fern allem gefährlichen Aktivismus, Radikalismus, Marxismus jener Jahre und wurde gleichwohl zum anklagenden Aufklärer.

Dieses Amt wurde er in den folgenden Jahren und Jahrzehnten nicht mehr los. Der Berg des Unrats, den Juristen der NS-Zeit hinterlassen hatten und nach dem Krieg eher vermehrten als abtrugen, war groß genug für die Schriften »Entartetes Recht «, »Wir denken die Rechtsbegriffe um ... u und zahllose Aufsätze. Und nun noch einmal: »Geschönte Geschichten - Geschonte Biographien «. »Der Autor und die Leser müssen sich damit abfinden, dass man nur selten etwas Neues, ein neues Nachdenken anstoßen kann, ohne Anstoß zu erregen «, bemerkt Rüthers nicht ohne vorauseilendes Selbstmitleid gegen Ende seines Essays. Was ist das Neue?

Neu ist, daß Rüthers die »Kohorte« entdeckt hat, wie schon der Untertitel bezeugt: "Sozialisationskohorten in Wendeliteraturen". Die Entdeckung dieser Kategorie zeitigt jedoch keine sensationellen Ergebnisse. Denn dass etwa gleichaltrige, aus ähnlichen Familienverhältnissen stammende Insassen des »Kitzeberger Lagers «, der Kaderschule des NS-Rechts, eine »Kohorte « bilden, ist ebenso plausibel wie es wenig überrascht, dass sie auch weiterhin ähnlich agierten, dachten und schrieben. Wollte man dieses Phänomen näher untersuchen, so müsste man wohl über die infektiösen Wirkungen einmal ausgelöster Kommunikationen, über zirkuläre und spiralförmige kommunikative Prozesse, über Anschlussfähigkeit bzw. -unmöglichkeit in diskursiven Zusammenhängen und Ähnliches nachdenken. Abrechnungen mit einzelnen Individuen der Kohorte - vgl. nur S. I 8-I 22 zu Karl Larenz - stehen jedenfalls quer zum Ansatz.

Neu - und wichtiger - ist, dass Rüthers "Wendeliteraturen « miteinander vergleicht. Stichjahre sind I919, I933, I945/49 und I989,

\footnotetext{
* Bernd Rüthers, Geschönte Geschichten - Geschonte Biographien. Sozialisationskohorten in Wendeliteraturen. Ein Essay, Tübingen: Mohr 200I, XII, I 68 S., ISBN 3-I 6-I 4765 I-4
}

\footnotetext{
I deren Autor inzwischen zu den "zivilrechtlichen Entdeckern " gezählt wird, vgl. die nachstehende Rezension von Natascha Doll.
} 
wobei die Daten I945/49 und I989 eine besondere Prominenz beanspruchen. Nach I945, so stellt Rüthers im Einklang mit eigenen und fremden Schriften fest, hat die NS-Juristenkohorte über die Vergangenheit geschwiegen (und über die schöne Gegenwart alsbald geschrieben). Nach I989 hat die DDR-Juristenkohorte über die Vergangenheit nicht geschwiegen, sondern, so Rüthers, munter weitergemacht. Zeugen dafür sind ihm natürlich nicht hunderte von abgewickelten, Taxi fahrenden oder Pizza austragenden, jedenfalls verstummten Juristen, sondern ein Häuflein von left overs (z. B. Karl A. Mollnau, Hermann Klenner, Karl-Heinz Schöneburg), die weiterhin öffentlich darüber nachdachten und nachdenken, ob denn die DDR nun wirklich ein vollkommener Unrechtsstaat war oder doch eher ein unvollkommener Rechtsstaat. Dieses obsessive Reden erbost Rüthers derart, dass er - statt über Wendeliteraturen zu räsonieren - mit in die Arena steigt, um die DDR endgültig und unabweisbar als Unrechtsstaat zu enttarnen, und dies nicht ohne en passant in den ersten und den zweiten Historikerstreit einzusteigen, Partei zu ergreifen, Nolte \& Co zu verteidigen, Geschichtsfälschungen anzuprangern. Mag Rüthers auch immer wieder betonen: »In diesem Beitrag geht es um den Vergleich von Sozialisationskohorten in Wendeliteraturen, nicht um einen materialen und qualitativen Vergleich der Systeme", so erweisen sich solche Formeln als Selbstbeschwörung und Selbstpurifikation. Der anklagende Aufklärer im Dauerdienst kann das Bekennen nicht lassen.

Was aber nun folgt aus dem Vergleich I945/ 49 und I989? Die einen schwiegen zur Vergangenheit, die anderen redeten weiter. Was man bei Ende eines Unrechtsregimes also auch tut: Schweigen oder Reden - Rüthers ist beides zu- tiefst zuwider. No way out? Den Weg aus dem Dilemma weist er nicht explizit auf, spricht nicht aus, was er erwartet, praktiziert aber, was er für geboten hält: Bekenne das Gute! Was auch heißt: Und gestehe das Böse! Schweigen gilt nicht, und nicht-reumütiges Reden gilt auch nicht. Geständnis erst hätte die Absolution in Aussicht stellen können, gleich ob I945 oder I989. Geständniszwang und Geständnisdrang sind alteuropäische Techniken, Sprachlosigkeit zu überwinden, sind Rechtfertigungsgründe für die prinzipielle und unausweichliche Fahrlässigkeit jeglichen Redens, sind in ihrer Befehlsstruktur "Maßnahmen « gegen den Rückzug in das Menschenrecht des Schweigens. Dem Befehl: »Gestehe! « widersetzt sich so leicht keiner, weder in der Talkshow noch im trauten Gespräch: »Larenz fragte sich I980 in dem Gespräch [mit Rüthers] selbst grübelnd ,War ich ein Nazi? - - War ich überzeugt von den 'fürchterlichen Sachen', die ich nach I934 geschrieben habe? « (I2 I). Grübelnde Gewissenserforschung ist die Vorstufe des Geständnisses, und Larenz war schon auf dem halben Weg zur Absolution.

Wer hohen Sinnes Bekenntnis praktiziert und Geständnis fordert, sollte nur eines nicht tun: sein eigenes Schicksal beklagen. "Das Erscheinen meiner Schrift >Die unbegrenzte Auslegung löste nicht nur kollegiale Ausgrenzungen seitens der betroffenen NS-Autoren und Berufungsblockaden in Fakultäten aus, welche Referenten des >Kitzeberger Lagers von 1935 in ihren Reihen hatten ...«(23), sondern Schlimmeres mehr. Man stelle sich vor, die Empörung wäre ausgeblieben! Dann hätte doch alles Aufklären, Anklagen und Bekennen gar keinen Sinn gehabt.

\section{Marie Theres Fögen}

